\title{
UNA ESPECIE NUEVA DE BURSERA (BURSERACEAE) DEL ESTADO DE GUERRERO, MÉXICO
}

JaIME JIMÉnEZ RAMíREZ

Y

Ramiro Cruz Durán

\author{
Herbario de la Facultad de Ciencias, UNAM \\ Apartado postal 70-399 \\ 04510 México, D.F.
}

\begin{abstract}
RESUMEN
Se describe Bursera martae como nueva para la ciencia. Esta planta se ha localizado en la parte media de la depresión del Balsas, en el estado de Guerrero, México. Bursera martae está relacionada con $B$. crenata $P$. G. Wilson y $B$. rzedowskii Toledo. Se incluye una clave dicotómica para distinguir las especies cercanas a este nuevo taxon.

Palabras clave: Bursera, Burseraceae, Guerrero, México.
\end{abstract}

\begin{abstract}
Bursera martae is described as a new species. It inhabits the middle region of the Balsas depression in the state of Guerrero, Mexico. It is closely related to B. crenata P. G. Wilson and B. rzedowskii Toledo. A dichotomous key to distinguish all related taxa to this new one is provided.

Key words: Bursera, Burseraceae, Guerrero, Mexico.

En las exploraciones botánicas efectuadas en el municipio General Heliodoro Castillo, en el estado de Guerrero, se encontró una especie de Bursera no catalogada con anterioridad, la cual se describe a continuación.

Bursera martae J. Jiménez Ram. \& Cruz-Durán. sp. nov. Fig. 1.

Frutex 3-4 m altus, dioecius; cortex griseus, fissuratus. Folia unifoliolata, elliptica, glabra, (4.1-)4.5-5.5(-6.4) cm longa, (2-)2.1-2.3(-2.8) cm lata, apice obtusa vel acuta, base cuneata usque rotundata, (9-)11-12(-13) paria nervorum; petiolus (4-)6-8(-11) mm longus. Inflorescentia mascula dichasiis, flos femineus solitarius. Flos masculus pentamerus, sepala triangulata, $1 \mathrm{~mm}$ longa; petala alba, lanceolata, 2-4 mm longa; stamina 10, $2 \mathrm{~mm}$ longa.
\end{abstract}




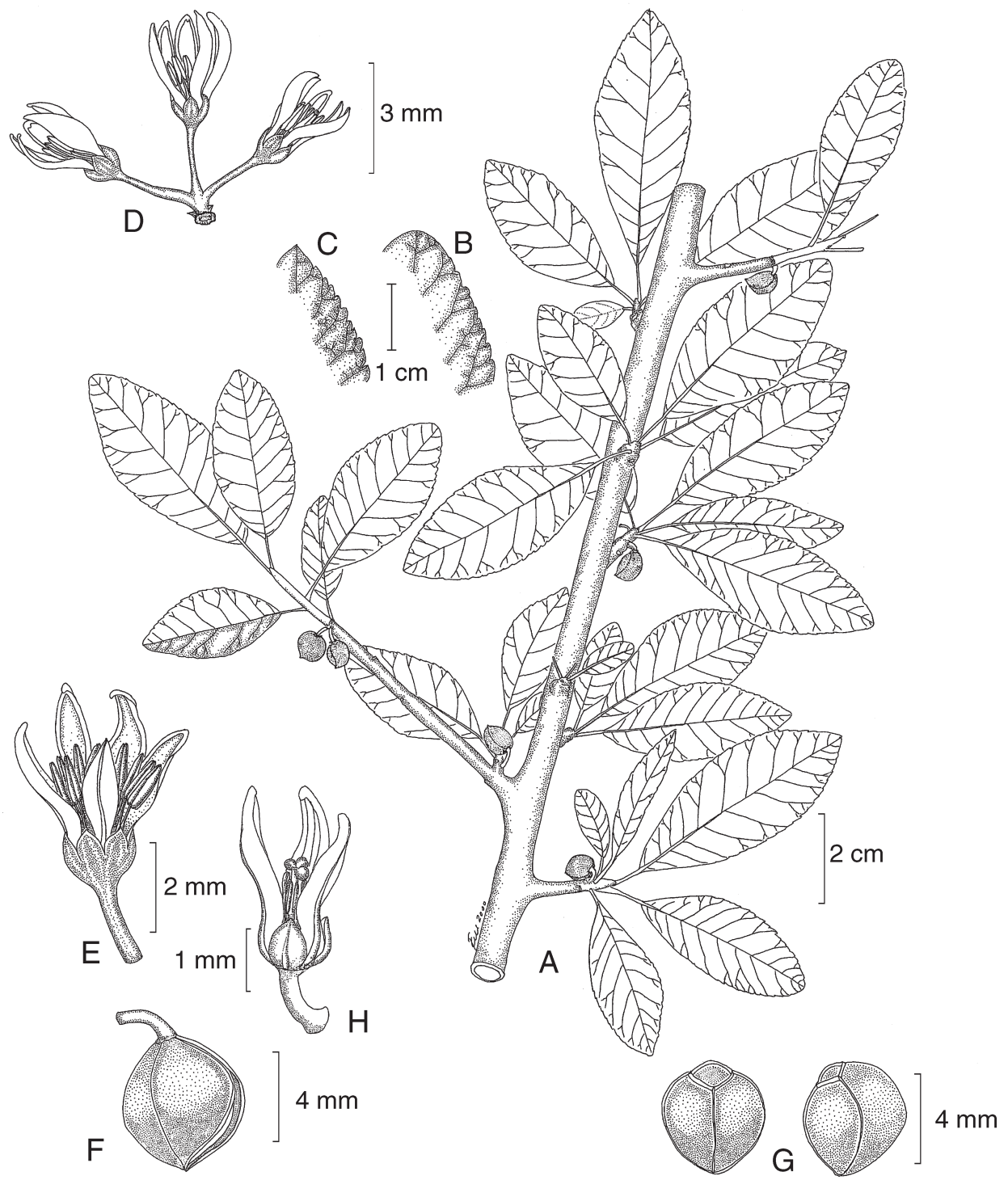

Fig. 1. Bursera martae J. Jiménez Ram. \& Cruz-Durán. A. Rama con frutos; B. Margen de una hoja con el ápice obtuso; C. Margen de una hoja con el ápice agudo; D. Dicasio de flores masculinas; E. Flor masculina; F. Fruto; G. Hueso en vista frontal y lateral, cubierto por pseudoarilo; H. Flor femenina. (A, B, F, G y H basado en R. Cruz Durán et al. 4799; C, D y E basado en R. Cruz Durán et al. 4806). 
Flos femineus trimerus, sepala triangulata, $1 \mathrm{~mm}$ longa; petala alba, lanceolata, (1.5-)2.5 (-3) $\mathrm{mm}$ longa, $1 \mathrm{~mm}$ lata. Drupae trivalvae, subsphaericae, 5-6 mm diametro. Putamen trigono-subsphaericum, 4-5 mm diametro, pseudoarillus viridis putaminem omnino tegens.

Arbusto de 3 a 4 m de alto, poco ramificado, glabro, dioico, caducifolio; corteza gris a rojiza, fisurada, poco exfoliante; hojas alternas en las ramillas jóvenes, aglomeradas a manera de roseta en las ramillas del año anterior, unifolioladas, elípticas a obovadas, glabras, de (4.1-)4.5 a 5.5(-6.4) cm de largo y de (2-)2.1 a 2.3(-2.8) cm de ancho, folíolo con (9-)11 a 12(-13) pares de venas secundarias, pecíolo de (4-)6 a 8(-11) mm de largo, ápice obtuso o agudo y base cuneada a redondeada, margen crenado-aserrado, con (19-)20 a 25(-30) dientes por lado, de 2 a 3(-4) mm de ancho; inflorescencias masculinas en dicasios reflejos, agrupados en los extremos de las ramillas cortas de los años anteriores, de hasta $6 \mathrm{~mm}$ de largo, con pedúnculos glabros, de ca. $1 \mathrm{~mm}$ de largo, las flores femeninas en la base de las ramillas nuevas, solitarias o en pares, reflejas; flores masculinas pentámeras, glabras, pedicelos de 1 a $2 \mathrm{~mm}$ de largo, sépalos triangulares, de $1 \mathrm{~mm}$ de largo, pétalos lanceolados, blancos, ascendentes, de 2 a $4 \mathrm{~mm}$ de largo y ca. $1 \mathrm{~mm}$ de ancho, estambres 10, de $2 \mathrm{~mm}$ de largo, anteras oblongas, amarillas, de 1 a $1.5 \mathrm{~mm}$ de largo, filamento de ca. $1 \mathrm{~mm}$ de largo, gineceo ausente; flores femeninas trímeras, glabras, sobre pedicelos curvos, de $1 \mathrm{~mm}$ de largo, sépalos 3 , triangulares, de $1 \mathrm{~mm}$ de largo, pétalos lanceolados, blancos, de (1.5-)2.5(-3) $\mathrm{mm}$ de largo y de $1 \mathrm{~mm}$ de ancho, estaminodios 6 , de $1.5 \mathrm{~mm}$, anteras amarillas, de ca. $1 \mathrm{~mm}$ de largo, gineceo de $1.5 \mathrm{~mm}$ de largo, ovario de ca. $1 \mathrm{~mm}$, estilo de ca. $1 \mathrm{~mm}$ de largo, estigma trilobulado; drupas trivalvadas, solitarias (en ocasiones pareadas) en la base de las ramillas nuevas, subesféricas, de $7 \mathrm{~mm}$ de largo en fresco y de 5 a $6 \mathrm{~mm}$ de largo cuando secas, hueso trígono-subesférico, verde claro, de 4 a $5 \mathrm{~mm}$ de diámetro, pseudoarilo verde pálido, cubriendo por completo el hueso.

Nombre común: Copal macho.

Florece en mayo y fructifica de junio a julio. En un ejemplar cultivado la aparición de flores femeninas y de hojas se presentó a mediados de abril.

La población conocida de Bursera martae es pequeña y está acompañada por $B$. xochipalensis Rzedowski, B. vejar-vazquezii Miranda, B. arborea (Rose) Riley, B. bipinnata (DC.) Engl. y B. discolor Rzedowski (con predominio de las dos últimas).

TIPO: México, Guerrero, mpio. Gral. Heliodoro Castillo, Tecomazúchil, $1 \mathrm{~km}$ al NE, $17^{\circ} 37^{\prime} 37^{\prime \prime N} 100^{\circ} 1^{\prime} 59.9^{\prime \prime O}$. Alt. $1420 \mathrm{~m}$, bosque tropical caducifolio, suelo calizo, asociado a Euphorbia sp., Plumeria sp., Leguminosae, Rubiaceae, Burseraceae, 9-jul-2000, Ramiro Cruz Durán, Javier Castrejón Reyna y Manuel García Granados 4799 (holotipo: FCME, isotipos: IEB, MEXU).

Material adicional examinado: México, Guerrero, mpio. Gral. Heliodoro Castillo. Tecomazúchil, $1.75 \mathrm{~km}$ al NE, cañada El Tigre, 17³7'23.3"N 100¹'55.9"O, Alt. $1470 \mathrm{~m}$, bosque tropical caducifolio, 5-jun-2000, Ramiro Cruz Durán y Karla Vega 4636 (FCME); Tecomazúchil, $1 \mathrm{~km}$ al $\mathrm{E}, 17^{\circ} 37^{\prime} 26.1^{\prime \prime} \mathrm{N} 100^{\circ} 1^{\prime} 56.1 " \mathrm{O}$, Alt. $1390 \mathrm{~m}$, bosque tropical 
caducifolio, suelo calizo, asociado a Euphorbia sp., Plumeria sp., Leguminosae, Rubiaceae, Burseraceae, 9-jul-2000, Ramiro Cruz Durán, Javier Castrejón Reyna y Manuel García Granados 4806 (FCME); Tecomazúchil, 1.53 km al NE, 17³7'35"N 100¹'58.5"O, Alt. 1415 m, bosque tropical caducifolio, 2-sep-2000, Ramiro Cruz Durán y Javier Castrejón Reyna 4899 (FCME).

La carencia de catáfilos bien desarrollados, la presencia de flores masculinas pentámeras, flores femeninas trímeras, drupas trivalvadas y la corteza gris-rojiza poco exfoliante, sugiere que B. martae pertenece a la Sección Bursera (sensu Toledo, 1982). La nueva especie difiere de $B$. schlechtendalii Engl. por sus hojas menos largas, el margen crenado-aserrado de las mismas y la presencia de mayor número de pares de venas secundarias; de B. rzedowskii Toledo lo hace por sus hojas más pequeñas, la consistencia papirácea de éstas, el tipo de margen, el pecíolo más largo, así como el habitat a mayor altitud, de $B$. trimera Bullock se separa por su margen crenado-aserrado, el ancho de los dientes marginales, drupas subesféricas, y hojas siempre unifolioladas, y de $B$. crenata $P$. G. Wilson por presentar menos pares de venas secundarias, menor número de dientes en el margen y de mayor tamaño y porque se distribuye a una mayor altitud. Se puede afirmar que $B$. martae guarda una relación más cercana con $B$. rzedowskii y $B$. crenata (Cuadro 1).

Clave para distinguir a Bursera martae de las especies unifolioladas que le son afines.

1 Folíolos con margen entero o parcialmente dentado.

2 Margen del folíolo siempre entero, con 8-9 pares de venas secundarias y ancho de 1.3-4.2 cm; con distribución desde Tamaulipas, San Luis Potosí y Jalisco hasta Centro América (incluyendo Yucatán), de 500 a 2250 m s.n.m. B. schlechtendalii

2 Margen del folíolo entero o parcialmente dentado, con (13-)14-15 pares de venas secundarias y ancho de $1.3-2.5 \mathrm{~cm}$; conocida exclusivamente de Tlalcozotitlán, Guerrero, de 600 a 1000 m s.n.m. B. rzedowskii

1 Folíolos con margen totalmente crenado, crenado-aserrado o aserrado-dentado.

3 Folíolos con 9-15 pares de venas secundarias, margen aserrado-dentado o crenadoaserrado y 19-30 dientes por lado; drupa trígona o subesférica.

4 Hoja trifoliolada y/o unifoliolada; foliolos obovado-oblanceolados u oblongos, margen aserrado-dentado, con 23-29 dientes por lado y (13-)14-15 pares de venas secundarias; drupa trígona; Depresión occidental del río Balsas, de 260 a $600 \mathrm{~m}$ s.n.m. B. trimera

4 Hoja estrictamente unifoliolada; foliolos elípticos a obovados, margen crenadoaserrado, con (19-)20-25(-30) dientes por lado y (9-)11-12(-13) pares de venas secundarias; drupa subesférica; conocida únicamente de Tecomazúchil, Gro., de 1390 a 1470 m s.n.m.

B. martae

3 Folíolos con (16-) 19-20 (-21) pares de venas secundarias, margen crenado y (32-)4853(-60) dientes a cada lado; drupa ovoide; endémica de la Depresión occidental del río Balsas, de 260 a 400 m s.n.m. B. crenata 
El epíteto específico está dedicado a la M. en C. Martha Martínez Gordillo, botánica mexicana especialista en Euphorbiaceae, quien ha contribuido de manera sustancial al conocimiento de la flora del estado de Guerrero, México.

Cuadro 1. Diferencias morfológicas entre B. martae y especies afines.

\begin{tabular}{|c|c|c|c|c|c|}
\hline & B. trimera* & B. schlechtendalii* & B. rzedowskii ${ }^{*}$ & B. crenata* & B. martae \\
\hline Hojas & $\begin{array}{l}\text { Unifolioladas } \\
\text { en las ramas } \\
\text { vigorosas, las } \\
\text { demás trifolio- } \\
\text { ladas }\end{array}$ & Unifolioladas & Unifolioladas & Unifolioladas & Unifolioladas \\
\hline $\begin{array}{l}\text { Largo-ancho del } \\
\text { folíolo }\end{array}$ & $3 \times 1.5 \mathrm{~cm}$ & $\begin{array}{l}1.7-7.9(-15) \times 1.3- \\
4.2 \mathrm{~cm}\end{array}$ & $\begin{array}{l}(2.3-) 3-7.5 x \\
1.3-2.5 \mathrm{~cm}\end{array}$ & $4-7 \times 1.5-2.2 \mathrm{~cm}$ & $\begin{array}{l}(4.1-) 4.5-5.5 \\
(-6.4) \times(2-) 2.1- \\
2.3(-2.8) \mathrm{cm}\end{array}$ \\
\hline Largo del pecíolo & ca. $10 \mathrm{~mm}$ & Inconspicuo & $1.4-5 \mathrm{~mm}$ & $5-8 \mathrm{~mm}$ & $(4-) 6-8(-11) \mathrm{mm}$ \\
\hline Forma del folíolo & $\begin{array}{l}\text { Obovada-oblan } \\
\text { ceolada u oblon } \\
\text { ga }\end{array}$ & $\begin{array}{l}\text { Elíptica a oblanceo } \\
\text { lada }\end{array}$ & $\begin{array}{l}\text { Angostamente } \\
\text { elíptica }\end{array}$ & $\begin{array}{l}\text { Angostamente } \\
\text { elíptica }\end{array}$ & $\begin{array}{l}\text { Elíptica a obo- } \\
\text { vada }\end{array}$ \\
\hline $\begin{array}{l}\text { Pares de venas } \\
\text { secundarias }\end{array}$ & (13-)14-15 & $8-9$ & (13-)14-15 & $(16-) 19-20(-21)$ & $(9-) 11-12(-13)$ \\
\hline Margen del folíolo & $\begin{array}{l}\text { Aserrado-den- } \\
\text { tado }\end{array}$ & Entero & $\begin{array}{l}\text { Entero (parcial- } \\
\text { mente dentado) }\end{array}$ & Crenado & $\begin{array}{l}\text { Crenado-ase- } \\
\text { rrado }\end{array}$ \\
\hline $\begin{array}{l}\text { Dientes o lóbulos } \\
\text { por lado del folíolo }\end{array}$ & 23-29 & Ausentes & $(-32)$ & $(32-) 48-53(-60)$ & $(19-) 20-25(-30)$ \\
\hline $\begin{array}{l}\text { Ancho de dientes } \\
\text { del margen }\end{array}$ & $1 \mathrm{~mm}$ & Ausente & $(1 \mathrm{~mm})$ & $1-2 \mathrm{~mm}$ & $2-3(-4) \mathrm{mm}$ \\
\hline $\begin{array}{l}\text { Consistencia del } \\
\text { folíolo }\end{array}$ & Papirácea & Papirácea & Coriácea & Papirácea & Papirácea \\
\hline Corteza & $\begin{array}{l}\text { Roja, exfolian- } \\
\text { te }\end{array}$ & Roja, exfoliante & $\begin{array}{l}\text { Rojiza, exfolian } \\
\text { te }\end{array}$ & $\begin{array}{l}\text { Rojiza, exfolian } \\
\text { te }\end{array}$ & $\begin{array}{l}\text { Gris-rojiza, fisu- } \\
\text { rada, poco ex- } \\
\text { foliante }\end{array}$ \\
\hline Drupa & $\begin{array}{l}\text { Trígona, } 6-8 \mathrm{~mm} \\
\text { de largo }\end{array}$ & $\begin{array}{l}\text { Obovoide, 5.1-8.5 } \\
\text { x 4-5.4(-7.5) } \mathrm{mm} \\
\text { de diámetro }\end{array}$ & $\begin{array}{l}\text { Globosa-elip- } \\
\text { soide, } 5-8 \mathrm{x} \\
4.3-6 \mathrm{~mm} \text { de } \\
\text { diámetro }\end{array}$ & $\begin{array}{l}\text { Ovoide, } 4-6 \mathrm{~mm} \\
\text { de largo }\end{array}$ & $\begin{array}{l}\text { Subesférica, } \\
7 \mathrm{~mm} \text { de largo }\end{array}$ \\
\hline $\begin{array}{l}\text { Distribución geo- } \\
\text { gráfica y altitud }\end{array}$ & $\begin{array}{l}\text { Depresión occi- } \\
\text { dental del Bal- } \\
\text { sas (Gro. y } \\
\text { Mich.), } 200-600 \\
\text { m s.n.m. }\end{array}$ & $\begin{array}{l}\text { Desde Tam., S.L.P., } \\
\text { Jal. hasta C. Amé } \\
\text { rica, } 500-2250 \mathrm{~m} \\
\text { s.n.m. }\end{array}$ & $\begin{array}{l}\text { Alrededores de } \\
\text { Tlalcozotitlán, } \\
\text { Gro., } 600-1000 \\
\text { m s.n.m. }\end{array}$ & $\begin{array}{l}\text { Depresión occi- } \\
\text { dental del Bal- } \\
\text { sas, } 260-400 \text { m } \\
400 \text { m s.n.m. }\end{array}$ & $\begin{array}{l}\text { Alrededores de } \\
\text { Tecomazúchil, } \\
\text { Gro., 1390- } \\
1470 \text { m s.n.m. }\end{array}$ \\
\hline
\end{tabular}

* Tomado en parte de Toledo (1982, 1984). 


\section{AGRADECIMIENTOS}

Los autores dan gracias a los revisores anónimos de la revista por el examen crítico del manuscrito, así como sus valiosas sugerencias. Asimismo, agradecen el apoyo de la Comisión Nacional para el Uso y Conocimiento de la Biodiversidad y de la Facultad de Ciencias de la Universidad Nacional Autónoma de México al proyecto R131 "Base de datos del municipio General Heliodoro Castillo, Gro.", ya que en el desarrollo de éste fue localizada la especie descrita en el presente trabajo.

\section{LITERATURA CITADA}

Toledo-Manzur, C. A. 1982. El género Bursera (Burseraceae) en el estado de Guerrero (México). Tesis de Licenciatura. Facultad de Ciencias. Universidad Nacional Autónoma de México. México, D.F. $182 \mathrm{pp}$.

Toledo-Manzur, C. A. 1984. Contribuciones a la flora de Guerrero: tres especies nuevas del género Bursera (Burseraceae). Biotica 9(4): 441-449. 